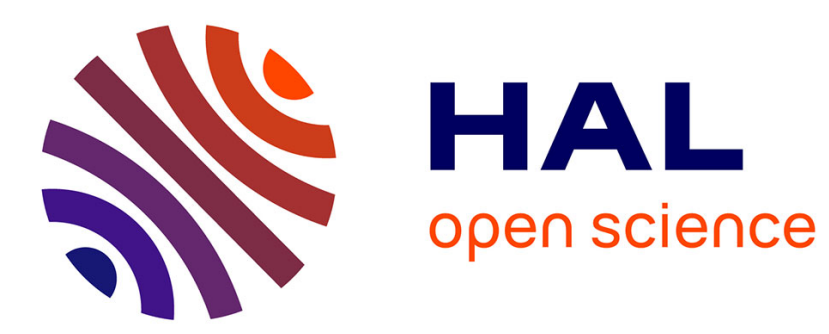

\title{
National Oligopolies and Economic Geography
}

Barbara Annicchiarico, Federica Orioli, Federico Trionfetti

\section{To cite this version:}

Barbara Annicchiarico, Federica Orioli, Federico Trionfetti. National Oligopolies and Economic Geography. 2011. halshs-00607641

\section{HAL Id: halshs-00607641 https://shs.hal.science/halshs-00607641}

Preprint submitted on 10 Jul 2011

HAL is a multi-disciplinary open access archive for the deposit and dissemination of scientific research documents, whether they are published or not. The documents may come from teaching and research institutions in France or abroad, or from public or private research centers.
L'archive ouverte pluridisciplinaire HAL, est destinée au dépôt et à la diffusion de documents scientifiques de niveau recherche, publiés ou non, émanant des établissements d'enseignement et de recherche français ou étrangers, des laboratoires publics ou privés. 


\section{GREQAM}

Groupement de Recherche en Economie Quantitative d'Aix-Marseille - UMR-CNRS 6579

Ecole des Hautes études en Sciences Sociales Universités d'Aix-Marseille II et III
Document de Travail $\mathbf{n}^{\circ} 2011-32$

National Oligopolies and Economic Geography

Barbara Annicchiarico

Federica Orioli

Federico Trionfetti

July 2011 


\title{
National Oligopolies and Economic Geography*
}

\author{
Barbara Annicchiarico $^{\dagger} \quad$ Federica Orioli $^{\ddagger} \quad$ Federico Trionfetti ${ }^{\S}$
}

\begin{abstract}
We replace monopolistic competition with national oligopolies in a model of "new economic geography". There are many possible bifurcation diagrams but, unlike in monopolistic competition, the symmetric equilibrium is always stable for low trade costs. The antitrust policy, though identical in both countries, affects the geographical distribution of firms. In turn, migration attenuates the effectiveness of the antitrust policy in eliminating collusive behavior. For high trade costs a toughening of the antitrust policy is likely to result in more agglomeration and may reduce world welfare. The antitrust policy is more likely to be welfare improving when market integration progresses.

JEL codes: R12, R13, F12. Keywords: Spatial Oligopoly, Antitrust Policy, Welfare.
\end{abstract}

${ }^{*}$ The authors are grateful for the comments and suggestions of three anonymous referees on an earlier version of the paper. The usual disclaimer applies. Maple files available from the authors upon request.

†Corresponding Author: Department of Economics, University of Rome "Tor Vergata", Via Columbia 2, 00133 Roma, Italy. Phone: +390672595731. Fax: +39062020500. E-mail address: barbara.annicchiarico@uniroma2.it.

$\ddagger$ University of Rome "Luiss Guido Carli". E-mail address: forioli@luiss.it.

§GREQAM, Université de la Méditerranée. E-mail address: federico.trionfetti@univmed.fr. 


\section{Introduction}

Monopolistic competition is the market structure typically assumed in models of the new economic geography. In this paper we replace the assumption of monopolistic competition with that of oligopoly. The main thrust or our paper is the study of national oligopoly. We argue that the extent of oligopoly interaction may be limited by national boundaries. Thus, firms may act as oligopolists in their home market and as monopolistic competitive firms in the foreign market. We show some corroborating evidence in support of this assumption.

In the presence of national dimensions there is a rich variety of stable spatial configurations which does not emerge in monopolistic competition. Further, the coreperiphery outcome is unstable for low enough trade costs. The intuition for this result is that for low trade costs the oligopolistic equilibrium price prevailing in the core is larger than the monopolistic-competitive price prevailing in the periphery, even though the latter price includes part of trade costs. As a result consumers will find it optimal to emigrate toward the smaller distant market and the core-periphery configuration is unstable. This result contrasts sharply with the result obtained in models of economic geography that assume monopolistic competition where, for low enough trade costs, the symmetric equilibrium is unstable.

We continue the analysis of national oligopoly by considering the possibility of collusive behavior in the presence of an antitrust policy. We find this interesting because it highlights the interaction between two seemingly unrelated policies: market integration and antitrust policy. Antitrust policies are designed to fight collusive behavior (here at national level), but have consequences on the equilibrium spatial configurations which depend on the degree of market integration. We trace a relationship between the intensity of the antitrust policy and the degree of spatial agglomeration. We find that for high trade costs, a toughening of the antitrust policy has a non-linear effect on the degree of agglomeration: first increasing it, then reducing it, and then increasing it again. For low enough trade costs a toughening of the antitrust policy has no impact on agglomeration. In addition, we show that the link between antitrust policy and agglomeration goes in both directions: agglomeration reduces the effectiveness of the antitrust policy in eliminating collusive behavior. The complex picture that emerges is the result of two opposing forces driving location decisions. On the one hand, the introduction of an anti-collusive fine tends to make the symmetric equilibrium unstable, since the higher the firms' agglomeration, the higher the extra-profits derived from colluding and, therefore, the higher the ability to pay the fine. On the other hand, under collusion a symmetric spatial configuration is more beneficial for consumers, since the higher prices prevailing in more agglomerated markets have a negative impact on their surplus.

Lastly, we measure the impact of the antitrust policy on world welfare. The antitrust policy influences welfare in two ways: the direct effect on prices and the indirect effect through the location of firms. We show that a toughening of the antitrust policy will have negative effects on world welfare when the negative effect resulting from an increase in agglomeration dominates the positive effect resulting from a reduction of prices. 


\section{Review of the Literature}

The literature on spatial oligopoly has a long tradition and it is beyond the scope of this paper to provide an exhaustive review. One of the earliest paper often cited is that of Hotelling (1929), he finds that competition for market areas leads to the agglomeration of firms. In Hotelling's model, two firms selling a single homogenous product at the same fixed price choose location on a line where customers are evenly distributed. Each firm gains by locating near to its competitor because, in so doing, it gains customers located between itself and the competitor without loosing customers located further away from the competitor than from itself. The result, known as the Principle of Minimum (spatial) Differentiation, is that firms will agglomerate in the center of the line. The agglomeration force is determined by the desire to increase the market share. Models of this type neglect an important aspect, namely, that firms want to be away from competitors in order to better exploit their market power. Taking this aspect into account, d'Aspremont et al. (1979) have shown that price competition leads to dispersion of firms. In their model the presence of trade costs makes goods spatially differentiated. In this situation, when a firm moves closer to its competitor the latter will react by lowering its price thus impacting negatively on the approaching firm's profits. This price competition effect pushes firms apart.

All the location theory is built upon the tension between agglomeration and dispersion forces, the former typically generated by the desire to be close to large markets in order to attract customers, and the latter generated typically by the desire to avoid price competition (or market crowding) effects. In most of this literature there is no interaction between firms location and size of the market. This interaction is brought in by Krugman (1991) who develops a model in monopolistic competition where the agglomeration and dispersion forces take a dynamic aspect. Firms want to locate in large markets because they want to attract customers (like in spatial competition), but (unlike in spatial competition) markets become larger precisely where firms decide to locate. Likewise, firms want to quit large markets in order to stay away from competition, but markets become less competitive precisely as firms quit them. Thus, the space feature in terms of market size becomes endogenous. This model has generated a vast literature known as the new economic geography (see Fujita et al. 1999; Fujita and Thisse, 2002; and Baldwin et al., 2003 for extensive treatments on the new economic geography). Most models in this literature assume monopolistic competition. Our model assumes oligopoly (like most of the spatial competition literature), but the size of the market depends on firms location (like in the new economic geography literature). To our knowledge only a few papers have ventured on the path of introducing oligopoly in a model of economic geography and none focuses on either the geographic extent of the oligopolistic interaction or on collusion and antitrust policy. The two papers that come closer to ours are Combes (1997) and Zhou (2007) who, using two versions of oligopoly different from ours, show that some of the results of monopolistic competition models of economic geography are confirmed in oligopoly; namely, that agglomeration occurs at low trade costs. We too, in passing, find this result (section 3.4). Combes (1997) continues his analysis by studying the consequences of initial cost advantages and size asymmetries. Zhou (2007) continues his paper by studying 
the effect of oligopoly on the composition of international trade and on technology adoption. Two other papers use oligopoly in an economic geography context, Ludema and Wooton (2000) and Dewit et al. (2003), but they focus on tax competition and on regulations in the labor market, respectively. ${ }^{1}$ Quite clearly, these papers address very different issues from those discussed here and none of them studies national oligopolies.

\section{The Model}

The majority of new economic geography models uses Dixit and Stiglitz (1977) preferences. This structure, however, does not lend itself easily to the treatment of oligopoly. We prefer to use the linear demand structure proposed in Ottaviano et al. (2002) which extends naturally to the treatment of an oligopolistic market. The extension we model is as follows.

The world economy is composed by two regions, Home, $H$, and Foreign, $F$, and produces two goods. ${ }^{2}$ One good is homogenous and is produced under perfect competition and constant returns to scale; we shall refer to this good as the "agricultural" good. The other good is horizontally differentiated and is produced by use of an increasing returns to scale technology in an oligopolistic market. In particular, there is a discrete number of firms $N$ each producing a variety different from any other variety. We shall refer to this good as "manufactures". Since we are interested in the study of oligopolistic behavior, we consider a market in which the number of producers is small, contrary to the original setup by Ottaviano et al. (2002) in which there is a continuum of firms.

There are two factors of production labeled as "workers" $(L)$ and "farmers" $(A)$, but each industry employs only one factor: the manufacturing sector uses only workers and the agricultural sector uses only farmers. Farmers are geographically immobile, while workers are mobile between regions. For the sake of symmetry, we shall assume that farmers are evenly distributed across the two regions. We assume that the homogenous good can be traded at no cost between regions. Its price is therefore identical in the two regions and we choose it as the numéraire. Each variety of the manufacturing good can only be traded across regions at the cost of $\tau>0$ units of the numéraire good for each unit of manufacture shipped. The cost $\tau$ accounts for all the obstacles to trade and is inversely related to market integration.

\subsection{Demand}

Individual preferences take the form of a quasi-linear utility function with a quadratic sub-utility that is assumed to be symmetric in all varieties and identical across indi-

\footnotetext{
${ }^{1}$ Head et al. (2002) study the pervasiveness of the home market effect in different market structures including oligopoly. The home market effect relates to economic geography in so far as it relates to the demand linkage present in models of economic geography. The focus of Head et al. (2002) is however on matters related to international trade rather than to economic geography.

${ }^{2}$ In the notation that follows, whenever confusion does not arise, we will focus on region $H$ since analogous equations and expressions for $F$ obtain by symmetry.
} 
viduals:

$$
U(q)=q_{0}+\alpha \sum_{i=1}^{N} q_{i}-\frac{\beta-\gamma}{2} \sum_{i=1}^{N} q_{i}^{2}-\frac{\gamma}{2}\left(\sum_{i=1}^{N} q_{i}\right)^{2},
$$

where $q_{i}$ is the quantity of variety $i$ and $q_{0}$ is the quantity of the numéraire good. ${ }^{3}$ All parameters are assumed to be positive. In particular $\beta>\gamma>0$, implies that consumers love variety. These assumptions ensure that the utility function is strictly concave. The parameter $\gamma$ measures the degree of substitution between any pair of varieties given $\beta$, so that goods are substitutes, independent, or complements according to whether $\gamma \gtreqless 0$. The larger $\gamma$ the closer substitutes goods are. If $\beta$ were allowed to be equal to $\gamma$, then goods would be perfect substitutes and the utility function would degenerate into a standard quadratic utility defined over a homogenous product. The parameter $\alpha$ indicates the intensity of consumers' preferences for differentiated goods.

Each individual is endowed with $\bar{q}_{0}>0$ units of the numéraire sufficient for positive equilibrium consumption and one unit of labor of type $L$ or $A$. Her budget constraint is defined as follows:

$$
\sum_{i=1}^{N} p_{i} q_{i}+q_{0}=m+\bar{q}_{0}
$$

where $p_{i}$ is the price of variety $i, m$ is labor income and the price of the agricultural good is normalized to one.

\subsection{Supply}

Good $A$ is produced by a constant returns to scale technology which requires one unit of labor input per one unit of output. The assumption that the agricultural good can be freely traded between regions implies that in equilibrium the wage of farmers is the same in both regions. The technology and the choice of the numéraire ensure that the common wage is equal to one.

Production of good $M$ requires $\phi$ units of $L$ for any quantity of output. This implies the assumption that variable costs are zero. Given the fixed input of workers, the market clearing conditions for $L$ imply that the number of varieties produced in each region, $n_{h}$ and $n_{F}$, is proportional to the number of workers present in each region at any time:

$$
\begin{gathered}
n_{H}=\frac{\lambda \bar{L}}{\phi}, \\
n_{F}=\frac{(1-\lambda) \bar{L}}{\phi},
\end{gathered}
$$

where $\lambda$ is the share of workers located in region $H$ and $\bar{L}$ is the stock of labor in the world economy. The total number of varieties produced in the economy is then $N=\frac{\bar{L}}{\phi}$. The equilibrium wage is determined as the result of a bidding process among firms demanding labor which, as a result of competition among firms, makes that the entire profit of the firm is absorbed by labor costs.

\footnotetext{
${ }^{3}$ As is well known the use of a quasi-linear utility function leads to ignore income effects.
} 
By solving the representative consumer's problem it can be easily shown that the demand functions faced by firm $i$ resident in $H$ in its domestic and foreign market are, respectively:

$$
q_{i, H H}=a-(b+c N) p_{i, H H}+c P_{H},
$$

and

$$
q_{i, H F}=a-(b+c N) p_{i, H F}+c P_{F},
$$

where $P_{H}, P_{F}$ are the price indices in region $H$ and region $F$ defined as $P_{H}=$ $\sum_{j=1}^{n_{H}} p_{j, H H}+\sum_{k=1}^{n_{F}} p_{k, F H}, P_{F}=\sum_{j=1}^{n_{H}} p_{j, H F}+\sum_{k=1}^{n_{F}} p_{k, F F}$, while $a \equiv \frac{\alpha}{\beta+\gamma(N-1)}, b \equiv$ $\frac{1}{\beta+\gamma(N-1)}$ and $c \equiv \frac{\gamma}{(\beta-\gamma)[\beta+\gamma(N-1)]}$. The parameters in the demand functions have a simple economic interpretation: $c$ is the cross-price effect, $c N$ is the sum of cross-price effects, and $(b+c N)$ is the own-price effect.

Profits in each market for firm $i$ resident in $H$ are:

$$
\begin{aligned}
\pi_{i, H H} & =p_{i, H H} q_{i, H H}\left(p_{i, H H}\right)\left(\frac{A}{2}+\lambda L\right), \\
\pi_{i, H F} & =\left(p_{i, H F}-\tau\right) q_{i, H F}\left(p_{i, H F}\right)\left[\frac{A}{2}+(1-\lambda) L\right],
\end{aligned}
$$

with $q_{i, H H}\left(p_{i, H H}\right), q_{i, H F}\left(p_{i, H F}\right)$ given by (5) and (6). Total profit is, therefore:

$$
\Pi_{i, H}=\pi_{i, H H}+\pi_{i, H F}-\phi w_{H},
$$

where $w_{H}$ is the manufacturing wage prevailing in region $H$.

Since demand is linear there is freight absorption. International trade will take place only if the price net of trade cost is positive (for any variety). Trade costs, therefore, must be sufficiently small in order for international trade to take place. We shall refer to $\tau_{\text {trade }}$ as the level of trade costs for which the price of any variety net of trade costs is positive for any distribution of workers between countries. By definition, there is international trade if $\tau<\tau_{\text {trade. }}$. As we shall see, the value of $\tau_{\text {trade }}$ depends on the market structure.

\subsection{Instantaneous Equilibrium and Dynamic Adjustment}

The distribution of farmers is exogenous and constant over time. Workers, instead, take migration decisions by comparing the indirect utility in $H, V_{H}$, with the indirect utility in $F, V_{F}$. The indirect utility is given by the sum of consumers surplus plus manufacturing wage plus endowment of the numéraire. The indirect utility difference, $\Delta V$, depends on $\lambda$ via the effect that $\lambda$ has on prices and on price indices. Denoting manufacturing wages $w_{H}, w_{F}$ and consumers surpluses $S_{H}(\lambda), S_{F}(\lambda)$ we have:

$$
\Delta V(\lambda) \equiv V_{H}(\lambda)-V_{F}(\lambda)=\left[S_{H}(\lambda)-S_{F}(\lambda)\right]+\left[w_{H}(\lambda)-w_{F}(\lambda)\right] .
$$

where the identical endowment of the numéraire cancels out. Labor and goods markets clear instantaneously. Migration is determined by the indirect utility difference according to

$$
\dot{\lambda} \equiv \frac{d \lambda}{d t}=\left\{\begin{array}{ccc}
\Delta V(\lambda), & \\
\min \{0, \Delta V(\lambda)\} & \text { if } & \lambda=1 \\
\max \{0, \Delta V(\lambda)\} & \text { if } & \lambda=0
\end{array}\right.
$$


where $t$ is time. The dynamic system is in a state of rest when $\dot{\lambda}=0$. Henceforth, we shall use the following terminology. We shall refer to any value of $\lambda$ as to a "spatial configuration". We shall often make reference to three spatial configurations to which we give the names of "symmetric spatial configuration" and "core-periphery configurations". The "symmetric spatial configuration" corresponds to $\lambda=1 / 2$ and the two core-periphery configurations correspond to $\lambda=0$ and to $\lambda=1$. A spatial configuration $\lambda^{*}$ is a "spatial equilibrium" if $\Delta V\left(\lambda^{*}\right)=0$. We see from (11) that in a spatial equilibrium the system is indeed in a state of rest since $\dot{\lambda}=\Delta V\left(\lambda^{*}\right)=0$. We see from equation (11) that the state of rest also occurs when $\lambda=1$ and $\Delta V(1)>0$ and when $\lambda=0$ and $\Delta V(0)<0$. In these two cases the indirect utility difference is different from zero but all workers have already migrated, therefore no further migration may occur.

A spatial equilibrium is locally stable if $\left.\frac{d \Delta V(\lambda)}{d \lambda}\right|_{\lambda=\lambda^{*}}<0$ and locally unstable if $\left.\frac{d \Delta V(\lambda)}{d \lambda}\right|_{\lambda=\lambda^{*}}>0$. The stability of spatial equilibria depends on parameter values. In particular, we shall refer to tau-break as to the value(s) of trade cost such that $\left.\frac{d \Delta V(\lambda)}{d \lambda}\right|_{\lambda=\frac{1}{2}}=0$ and we shall denote this value (or these values) $\tau_{b}$. Thus, $\tau_{b}$ is a value of trade costs at which the symmetric equilibrium switches from being stable to being unstable or viceversa. A core-periphery configuration which is not a spatial equilibrium is a stable configuration if the system is at rest. We shall refer to tau-sustain as to the value(s) of trade costs such that $\Delta V(0)=\Delta V(1)=0$ and we shall denote this value (or these values) $\tau_{s}$. Thus, $\tau_{s}$ is a value of trade costs at which the core-periphery configurations switch from being stable to being unstable or viceversa. In the presence of national oligopolies there may be more than one tau-break and more than one tausustain. In one case the critical values $\tau_{s}$ and $\tau_{b}$ coincide, in this case we denote both of them $\tau_{c}$. We refer to the "economic geography" as to the ensemble of stable spatial configurations and to their position in $(0,1)$ for given values of parameters.

\subsection{National Oligopoly}

In monopolistic competition each firm neglects the impact that its decision has on market aggregates. Thus, for instance, when the monopolistic-competitive firm decides its own price it neglects the impact that its decision has on the price index or, alternatively, when it decides the quantity of output it neglects the impact that its decision has on total market output. Conversely, in oligopoly each firm takes into account the effect that its action has on market aggregates. The extent of this awareness, however, may be limited by geographical distance. Because of insufficient information on distant markets a firm may ignore or consciously decide to neglect the impact that its action has on the distant market. We therefore distinguish between two cases: international oligopoly and national oligopolies.

In international oligopoly each firm is aware of the impact that its own decision has on world aggregates. Thus, for instance, when the firm decides its own price it takes into account the effect that its decision has on the price indices in both countries.

In national oligopolies, instead, each firm takes into account only the effect that its 
decision has on national market aggregates and neglects the impact that its decision has on world aggregates. Thus, for instance, when the firm decides its price it takes into account the effect that its decision has on the price index of its country and neglects the impact that it has on the price index of the foreign country. The resulting market structure is that firms in each country behave as oligopolist in their home market and as monopolistic-competitive firms in their distant market.

Evidence that the strategic horizon of firms is limited by geographical bounderies may be gathered by observing their collusive behavior. Table 1 contains information on cartel cases decided by the European Commission in the period 2001-2009 each of which concerning one member country market (local cartels). Each cartel case reported concerns a single proceeding in which the Commission imposed fines on various undertakings involved. We notice that 88 out of 101 of companies being part of the local cartels were domestic companies. Out of the fourteen cartels, seven can be classified as entirely national, i.e., involving only firms of the same nationality; five may be classified as quasi-national, i.e., where all but one firm have same nationality; and in only one cartel foreign firms are the majority. Further evidence is found in the data reported by the European Commission Directorate General for Competition which shows that between 2001-2009 over 75 percent of companies involved in European cartels were European companies or European subsidiaries of Japanese or US multinationals. ${ }^{4}$ Furthermore, according to the database compiled by Connor (2005, $2007)^{5}$, of the 388 markets (where by market is meant the industry or product subject to price fixing) in the sample, $64 \%$ were cartelized by national agreements affecting only the domestic commerce and involving only domestic companies.

Indirect evidence that firms behavior is different within than across borders is provided by the literature on the "border effect" which shows that trade volumes decline sharply when trade takes place across borders, ceteris paribus (see, e.g., McCallum, 1995; Head and Mayer, 2000). These facts and empirical evidence suggest that firms behavior and perception in and of the domestic market and domestic competitors is different from their behavior and perception in and of the foreign market and competitors. After all, this is not surprising. Business interactions, like other human interactions, are influenced by the cultural and legal environments which, in turn, are often defined by national boundaries. It becomes therefore interesting to distinguish between national and international oligopolies when studying the effect of the market structure and antitrust policies on economic geography and welfare.

In the remainder of the paper, for reason of space, we present only the results of the national oligopoly case. This is indeed the most interesting case since it gives results that are very different from those of monopolistic competition. The international oligopoly case instead gives results similar to those of monopolistic competition except for a difference that we briefly discuss here. The difference is in that the likelihood of stable core-periphery configuration (complete agglomeration) is higher in international oligopoly than in monopolistic competition; more technically, the value of $\tau_{c}$ in

${ }^{4}$ See the decisions made by the European
http://ec.europa.eu/competition/cartels/cases/cases.html Commission at
${ }^{5} \mathrm{We}$ refer to the updated data tables (2010)
http://www.agecon.purdue.edu/staff/connor/papers/Price_Fixing_Overcharges_Appendix_Tables.pdf


oligopoly is larger than the value of $\tau_{c}$ in monopolistic competition (see Appendix A). The reason is due to the fact that in the case of oligopoly the procompetitive effect of trade liberalization is larger than in monopolistic competition. Equilibrium prices in oligopoly, in fact, are more sensitive to changes in trade costs than equilibrium prices in monopolistic competition. As a consequence of firms' awareness of their market influence, a deeper market integration will increase the perceived demand elasticity facing domestic oligopolistic firms by more than under monopolistic competition. Oligopolistic firms are thus inclined to decrease prices by more in order to adjust their markups to the optimal level.

This difference besides, assuming international oligopolies gives qualitative results similar to those of monopolistic competition. We now turn to the study of national oligopolies.

\section{National Oligopoly and Economic Geography}

In this section we consider the case in which each firm takes account of the impact that its action has on national aggregate variables only. Each firm in $H$ maximizes (9) with respect $p_{i, H H}$, taking into account the effect on $P_{H}$, and maximizes it with respect to $p_{i, H F}$, neglecting the effect on $P_{F}$. The four equilibrium prices are:

$$
\begin{gathered}
p_{i, H H}^{N C}=\frac{2(2 b+c N)(b+c N)}{2(2 b+c N)(b+c N)-c(2 b+c N+c N \lambda)} p_{H H}^{M C}, \quad \forall i=1 . . n_{H}, \\
p_{i, F F}^{N C}=\frac{2(2 b+c N)(b+c N)}{2(2 b+c N)(b+c N)-c[2 b+c N+c N(1-\lambda)]} p_{F F}^{M C}, \quad \forall i=1 . . n_{F}, \\
p_{i, H F}^{N C}=\frac{a+c N(1-\lambda) p_{F F}^{N C}+(b+c N) \tau}{2 b+c N+c N(1-\lambda)}, \quad \forall i=1 . . n_{H}, \\
p_{i, F H}^{N C}=\frac{a+c N \lambda p_{H H}^{N C}+(b+c N) \tau}{2 b+c N+c N \lambda}, \quad \forall i=1 . . n_{F},
\end{gathered}
$$

where the superscript $N C$ indicates equilibrium prices in non-collusive national oligopolies and the superscript $M C$ indicates the equilibrium prices in monopolistic competition: $p_{H H}^{M C}=\frac{2 a+c(1-\lambda) N \tau}{2(2 b+c N)}$ and $p_{F F}^{M C}=\frac{2 a+c \lambda N \tau}{2(2 b+c N)}$. As is intuitive, $p_{H H}^{N C}>p_{H H}^{M C}$ and $p_{F F}^{N C}>p_{F F}^{M C}$. Further, $\frac{d p_{H H}^{N C}}{d \tau}>\frac{d p_{H H}^{M C}}{d \tau}$ and $\frac{d p_{F F}^{N C}}{d \tau}>\frac{d p_{F F}^{M C}}{d \tau}$, implying a stronger procompetitive effect of market integration in national oligopolies than in monopolistic competition. As in the case of international oligopolies, this result follows from the higher sensitivity of oligopolistic markups to changes in the level of market integration.

We observe that equilibrium national oligopoly prices may be different between countries even in the absence of transport costs whenever $\lambda \neq 1 / 2$. This result marks an interesting difference with the cases of international oligopoly and of monopolistic competition. Mathematically, this is due to the fact that with national oligopolies equilibrium prices are function of $\lambda$ and $\tau$ separately. Intuitively, the result is due to the national extent of the oligopolistic markets which makes the oligopoly equilibrium price in each market dependent on the size of that market. As a consequence the 
indirect utility difference $\Delta V$ ceases to be a linear function of $\lambda$ and new interaction between agglomeration and centrifugal forces opens up. This leads to a complex picture when we look at the stability of the spatial equilibria.

As shown in Appendix B, when we look at the stability of the symmetric equilibrium, there may be two distinct positive tau-break. When this is the case we denote the smallest and the largest of these two values $\tau_{b 1}^{N C}$ and $\tau_{b 2}^{N C}$, respectively. Similarly, when we look at the stability of the core-periphery configurations, we find that there may be two distinct and positive tau-sustain. When this is the case we denote the smallest and the largest of these two values $\tau_{s 1}^{N C}$ and $\tau_{s 2}^{N C}$, respectively.

As a result of the multiplicity of critical threshold levels of trade costs there are quite a few different possible bifurcation diagrams. In particular, it can be shown that the model may deliver a total of sixteen possible bifurcation diagrams. For reason of space we do not show the nine bifurcation diagrams that would result if either $\tau_{b 1}^{N C}=\tau_{b 2}^{N C}$ or $\tau_{s 1}^{N C}=\tau_{s 2}^{N C}$. Instead we consider the bifurcation diagrams when we have four distinct thresholds for trade costs, as in the four subcases plotted in Figure 1, when the model delivers two tau-sustain, but no tau-break, as in Figure 2, two tau-break, but no tau-sustain, as in Figure 3, and neither tau-sustain nor tau-break as in Figure 4, where the centrifugal forces dominate and the symmetric equilibrium is the only stable outcome.

Looking at the bifurcation diagrams we see that for sufficiently low and sufficiently high trade costs the only stable spatial configuration is the symmetric equilibrium. For intermediate trade costs, instead, there is a rich taxonomy of stable spatial configurations.

The economic geography resulting from national oligopoly is very different from that emerging in international oligopoly or in monopolistic competition. Pricing decisions depend on firms location and on transportation costs given the asymmetry of firm's behavior in the two markets. Oligopolistic interaction in the domestic markets exacerbates the effects of transportation costs on domestic prices (through a stronger effects on markups as in the case of international oligopoly) and on the reward of the mobile factor. Moreover, changes in $\tau$ determine changes in the level of market competition in the foreign market. In particular, we obtain the following results.

First, in the case of national oligopolies the symmetric configuration and the coreperiphery configurations may all be stable, whereas in the case of non-collusive international oligopoly (or in monopolistic competition à la Ottaviano et al., 2002), when the symmetric configuration is stable the core-periphery configurations are unstable and viceversa. The simultaneous stability of the symmetric and core-periphery spatial configurations occurs in Figure 1b for $\tau \in\left(\tau_{s 1}, \tau_{b 1}\right)$, and for $\tau \in\left(\tau_{b 2}, \tau_{s 2}\right)$, in Figure 1c for $\tau \in\left(\tau_{b 2}, \tau_{s 2}\right)$, and in Figure 1d for $\tau \in\left(\tau_{s 1}, \tau_{b 1}\right)$. This overlap can be explained as follows. For levels of $\tau$ sufficiently high workers earn a higher wage when they are located in only one region. Given the oligopolistic structure of the domestic markets, in fact, agglomeration is the source of extra profits which translate into higher wages exaggerating the market size differences. As a consequence, a core-periphery equilibrium can be sustained at levels of $\tau$ where the symmetric equilibrium is still stable.

Second, in the case of national oligopolies there may be multiple stable partial agglomerations. This result occurs neither international oligopoly nor in most $\overline{\text { models }}$ 
of monopolistic competition. Multiple stable spatial equilibria are shown in Figure 1a for $\tau \in\left(\tau_{b 1}, \tau_{s 1}\right)$, and for $\tau \in\left(\tau_{s 2}, \tau_{b 2}\right)$, in Figure 1c for $\tau \in\left(\tau_{b 1}, \tau_{s 1}\right)$, in Figure 1d for $\tau \in\left(\tau_{s 2}, \tau_{b 2}\right)$ and in Figure 3 for $\tau \in\left(\tau_{b 1}, \tau_{b 2}\right)$. Intuitively, the existence of stable partial agglomerations could be the result either of a higher degree of substitutability between goods or of higher relative dimension of the agriculture sector. Both forces reduce the extra profits in concentrated markets, so that full agglomeration ceases to be sustained while the symmetric spatial configuration is not yet stable.

Third, as shown by all bifurcation diagrams, in the case of national oligopolies the symmetric spatial configuration is stable for low transport costs.

This result marks an important difference with respect to the case of international oligopoly and monopolistic competition, where the symmetric configuration is unstable for low trade costs. ${ }^{6}$ In order to illustrate this result in detail we evaluate the two components of the indirect utility difference in expression (10) at one of the coreperiphery configuration, for instance for $\lambda=1$. When all firms are in $H$ we have that both the consumer surplus and the wage are lower in $H$ than in $F$ :

$$
\begin{aligned}
& S_{H}^{N C}(1)<S_{F}^{N C}(1), \\
& w_{H}^{N C}(1)<w_{F}^{N C}(1) .
\end{aligned}
$$

Therefore

$$
\Delta V(1)<0
$$

and the core-periphery configuration is unstable. ${ }^{7}$ The inequality in (16) is due the fact that for sufficiently low transportation costs when all firms are located in $H$ we have that $p_{H F}^{N C}<p_{H H}^{N C}$. The reason is due to the national dimension of the oligopoly: recall that firms set oligopoly prices in their national market and set monopolisticallycompetitive prices in their distant market. When all firms are in $H$ then the equilibrium price in $H$ is oligopolistic, while the equilibrium price in $F$ is monopolisticcompetitive. The oligopoly price is higher than the monopolistic competitive price. The latter, however, includes trade costs since all firms are in $H$. But if trade costs are sufficiently low then we have $p_{H F}^{N C}<p_{H H}^{N C}$ and, therefore, we have a higher consumers' surplus in $F$ than in $H$.

The inequality in (17) is explained by the balance of the size effect on gross profits. The largest local profit is made on the largest market; that is, for $\lambda=1, \pi_{H H}^{N C}>\pi_{F F}^{N C}$. Because of this effect, wages would tend to be higher in $H$ and agglomeration in $H$ would tend to be stable. But the size effect is present in profits on distant market too. The largest profit on the distant market is made on the largest distant market; that is, for $\lambda=1, \pi_{H F}^{N C}<\pi_{F H}^{N C}$. Because of this effect, wages would tend to be higher in $F$ and agglomeration in $H$ would tend to be unstable. For low trade cost, the size effect on distant markets profits dominates that on local markets profits. Thus, we have inequality (17).

\footnotetext{
${ }^{6}$ In the new economic geography literature there are a few models where core-periphery configurations are unstable for low trade costs and/or there are multiple spatial equilibria, but this is due to the presence of congestion forces or diminishing returns added to the models and not to the market structure per se. See, for instance, Helpman (1998), Puga (1999), Brülhart and Trionfetti (2004).

${ }^{7}$ See Appendix B for the proof.
} 
Last, computing tau-trade for national oligopolies gives $\tau_{\text {trade }}^{N C}=a \frac{2(c N+b)-c}{(c N-c+2 b)(b+c N)}<\frac{a}{b}$. Depending on parameter values $\tau_{\text {trade }}^{N C}$ can be larger or smaller than any of the tau-break and tau-sustain. The bifurcation diagrams should therefore be interpreted taking into account that the maximum meaningful value of trade cost is $\tau_{\text {trade }}^{N C}$ (not shown in the diagrams). The spatial configurations to the right of $\tau_{\text {trade }}^{N C}$ will, of course, never occur. ${ }^{8}$

The results of this section may be summarized as follows.

Proposition 1 In national oligopolies there are sixteen possible types of bifurcation diagrams, there may be multiple stable spatial configurations, stable partial agglomeration, and there exists a sufficiently low level of trade costs for which the symmetric equilibrium is stable.

Multiple stable spatial configurations, partial agglomeration, and stability of the symmetric equilibrium for low trade costs result solely from the assumption of national oligopoly. If we had assumed international oligopoly or monopolistic competition we would have either one or two stable spatial configurations, partial agglomeration would never be a stable configuration, and we would always have stable agglomeration for low trade costs. Proposition 1 shows that the conclusion drawn from the economic geography literature based on monopolistic competition are very sensitive to the assumption about the market structure and should therefore be taken with due caution.

\section{Collusion and Antitrust Policy}

The possibility of collusion among producers is always present in oligopolistic markets and antitrust laws have been a constant threat to collusive behavior. ${ }^{9}$ The objective of antitrust policies is to fight collusive behavior and is usually unrelated to international trade or to economic geography. Yet, there is an interaction between antitrust policies and location that we want to illustrate in this section. ${ }^{10}$

The collusive behavior is defined as follows: firms located in the same country, say $H$, maximize jointly the sum of profits on domestic markets:

$$
\underset{p_{H H}}{\operatorname{Max}}\left[n_{H} \pi_{H H}\left(p_{H H}\right)\right],
$$

and each firm maximizes individually its profits on the distant market:

$$
\underset{p_{i, H F}}{\operatorname{Max}}\left[\pi_{H F}\left(p_{i, H F}\right)\right] .
$$

\footnotetext{
${ }^{8}$ A similar truncation of the phase diagram occurs in Ottaviano et al. (2002) where, in monopolistic competition, the single tau-break coincides with the single tau-sustain and where tau-trade may be smaller than these.

${ }^{9}$ An early example of antitrust law is the Lex Julia de Annona, enacted during the Roman Republic around $50 \mathrm{BC}$.

${ }^{10} \mathrm{We}$ mention in passing that the stability analysis of collusive national oligopoly gives analogous results to that of non-collusive national oligopolies (see Appendix C). Again, there are sixteen possible types of bifurcation diagrams which are qualitatively the same as those of the non-collusive national oligopolies. Naturally, the values of tau-break and tau-sustain of non-collusive national oligopolies need not to coincide with those of collusive oligopoly.
} 
By solving the four maximization problems we obtain equilibrium prices:

$$
\begin{gathered}
p_{H H}^{C}=\frac{2(2 b+c N)(b+c N)}{2(2 b+c N)(b+c N)-c \lambda N(2 b+c N+c N \lambda)} p_{H H}^{M C}, \\
p_{F F}^{C}=\frac{2(2 b+c N)(b+c N)}{2(2 b+c N)(b+c N)-c N(1-\lambda)[2 b+c N+c N(1-\lambda)]} p_{F F}^{M C}, \\
p_{H F}^{C}=\frac{a+c N(1-\lambda) p_{F F}^{C}+(b+c N) \tau}{2 b+c N+c N(1-\lambda)}, \\
p_{F H}^{C}=\frac{a+c N \lambda p_{H H}^{C}+(b+c N) \tau}{2 b+c N+c N \lambda},
\end{gathered}
$$

where the superscript $C$ indicates equilibrium prices in collusive national oligopolies. Like in the previous section, and very intuitively, oligopoly prices are higher than monopolistic competitive prices, they are more sensitive to changes in trade costs, and are different in different markets even if trade cost is zero.

We now illustrate, by use of a numerical simulations, the effect of the antitrust policy on the economic geography and welfare. We limit our attention to collusive national oligopolies since this is the most interesting case. ${ }^{11}$ The case of collusive international oligopoly may be studied analogously. As expected, the antitrust policy, if severe enough, will eliminate collusive behavior. What is more interesting is that the antitrust policy has an indirect effect on the economic geography. We illustrate this effect in the context of two numeric examples of high and low trade costs. We shall see that the antitrust policy may have a different impact on the economic geography depending on the degree of economic integration. In this section we do not intend to draw general results. The intricacy of the algebra and the large number of parameters make a general demonstration or a complete taxonomy beyond the scope of the paper. Rather, we want to highlight the economic mechanism through which the antitrust policy influences the economic geography.

We have chosen parameter values (reported in Table 2) such that the collusive and non-collusive bifurcation diagrams are very different: the bifurcation diagram for non-collusive oligopoly is of the type represented in Figure 1a, whereas the bifurcation diagram for collusive-oligopoly is of the type represented in Figure 3. Given the same parametrization we notice that firms' collusive behavior acts as an important centrifugal force through the negative effects that higher prices would have on consumers' surplus in agglomerated markets. Therefore, an antitrust policy that eliminates collusive behavior is subject to impact the economic geography in an important way.

The antitrust policy we consider is extremely simple. We assume that each government fines firms who are found guilty of collusive behavior. Governments apply a fine equal to a fraction $\psi$ of local profits. Enforcement of anti-collusive regulations is not perfect and each collusive firm faces a probability $\delta$ of being fined. Thus, the expected fine for a collusive firm is a fraction $\eta=\psi \delta$ of local profits. Firms will collude if

$$
(1-\eta) \pi_{i i}^{C}-\pi_{i i}^{N C}>0, \quad i=H, F
$$

\footnotetext{
${ }^{11}$ We know from the industrial organization literature that collusion is sustainable in repeated games when the discount rate is sufficiently low. We assume that this is the case without explicitly modelling the sustainability of collusive behavior.
} 
Firms will not collude if the sign of the inequality is reversed. Firms are indifferent between colluding and not colluding when $(1-\eta) \pi_{i i}^{C}-\pi_{i i}^{N C}=0$, in such case we assume that the status quo prevails. Thus, if firms were not colluding before becoming indifferent they will continue not to collude when they become indifferent; if firms were colluding before becoming indifferent they will continue to collude when they become indifferent. Obviously, if $\eta=0$ firms will collude since collusive profits, $\pi_{i i}^{C}$, are larger than non-collusive profits, $\pi_{i i}^{N C}$.

It can be shown that for every spatial configuration there exists a unique expected fine rate $\eta$ for which firms are indifferent between colluding or not. ${ }^{12}$ Further, it can be easily shown that for firms located in $H(F)$ the critical level of $\eta$ is always increasing (decreasing) in $\lambda$. The economic intuition for this is straightforward. The higher the number of colluding firms located in the same region, the higher the gains from colluding and, therefore, the higher the fraction of profits that colluding firms can afford paying as a fine.

Figure 5 shows the combinations of $\eta$ and $\lambda$ for which firms operating in $H$ and $F$ collude or not. In the dark-gray area firms in both countries collude, thus we have two collusive national oligopolies. In the light-gray area firms collude in $H$ or in $F$ but not in both; note that it is firms in the largest market who collude. In the white areas firms in neither country collude. We have marked two threshold values of $\eta$ : $\eta=0.1247$, and $\eta=0.6694$ for future reference.

We can visualize the effect of the antitrust policy on the economic geography by use of phase diagrams. Each phase diagram plots the phase line given by the indirect utility difference as function of $\lambda$. We have seen in Figure 5 that, for a given $\eta$, by moving along the abscissa we cross different competition regimes. ${ }^{13}$ In turn, to each competition regime there corresponds a phase line. Therefore, each phase line shown in the diagrams pulls together the sections of the phase lines corresponding to the competition regime applicable to any value of $\lambda$. The resulting phase line, composed by these sections, will present discontinuities for values of $\lambda$ where the competition regime is subject to change.

We begin with the example of high trade costs where we set $\tau=1.73$. For this value of trade costs there is trade in all competition regimes (see Table 2).

Each panel in Figure 6 represents a phase diagram for six different values of $\eta$. In each diagram, we plot the phase line represented by the indirect utility difference $\Delta V(\lambda)$.

Figure 6 a plots the indirect utility difference in the absence of antitrust policy (i.e. $\eta=0)$. For $\eta=0$ firms in both countries collude for any value of $\lambda$ as we have already seen. There are three equilibria: the symmetric equilibrium which is unstable and two stable lateral equilibria with partial agglomeration. As already mentioned, the collusive behavior in the domestic markets tends to make full agglomeration unstable through the negative effects that higher prices have on consumers' surplus.

Figure $6 \mathrm{~b}$ plots the indirect utility difference for $\eta=0.04$. The phase line exhibits

\footnotetext{
${ }^{12}$ In Appendix D we demonstrate that the locus in the space $(\lambda, \eta)$ in which $(1-\eta) \pi_{i i}^{C}-\pi_{i i}^{N C}=0$ does not depend upon the level of economic integration $\tau$.

${ }^{13}$ For instance, with $\eta=0.2$, moving along the abscissa we cross from the area of collusion in $F$ to the area of no-collusion, to the area of collusion in $H$.
} 
two stable spatial equilibria on either side of the symmetric equilibrium. All firms collude when $\lambda \in(0.3217,0.6783) .{ }^{14}$ The stable spatial configurations are within the zone of collusion. We conclude that for $\eta=0.04$ there will be partial agglomeration with collusive national oligopolies. As mentioned above, we observe the discontinuities of the phase line for $\lambda=0.3217$ and $\lambda=0.6783$ where the competition regime is subject to change. For any value of $\lambda$ in the range $(0.6783,1]$ only firms in $\mathrm{H}$ collude. As a result prices will be higher in $\mathrm{H}$ than in $\mathrm{F}$, extra profits will be higher, but consumers surplus will be lower. The latter effect dominates the former and the economy will move towards the point $\lambda=0.6783$. By symmetry, any configurations in the interval $[0,0.3217)$ cannot be stable.

Figure 6c plots the indirect utility difference for $\eta=0.08$. Firms collude for $0.4193<\lambda<0.5807 .{ }^{15}$ Again for these values of $\eta$ the phase line exhibits a discontinuity. The consequence of these discontinuities is that there is no real value of $\lambda$ such that $\Delta V(\lambda)=0$. In other words, there is no spatial equilibrium. The absence of a spatial equilibrium bears no consequences on the determination of the stable spatial configuration. It is apparent that for any initial value of $\lambda \in\left(\frac{1}{2}, 1\right]$ the law of motion (11) will drive $\lambda$ towards 0.5807 . Conversely, for any value of $\lambda \in\left[0, \frac{1}{2}\right)$ the law of motion (11) will drive $\lambda$ towards 0.4193 . Or, equivalently, the sets $\left(\frac{1}{2}, 1\right]$ and $\left[0, \frac{1}{2}\right)$ are the basins of attraction of the limit points 0.5807 and 0.4193 , respectively. We conclude that for $\eta=0.08$ there is partial agglomeration and firms in the smallest country are indifferent between colluding and not colluding while firms in the largest country collude. We further note that the stable spatial configurations in Figure 6c are closer to each other than those in Figure 6b; firms are less dispersed.

Figure $6 \mathrm{~d}$ plots the indirect utility difference for $\eta=0.1247$. It can be shown (see Appendix D) that in this case firms are indifferent between colluding and not colluding when $\lambda=0.5$, for $\lambda<0.5$ firms in $F$ collude and firms in $H$ do not, for $\lambda>0.5$ firms in $H$ collude and firms in $F$ do not. There is, therefore, a discontinuity of the phase line at $\lambda=0.5$. This value of $\eta$ is marked in Figure 5. It is apparent that the symmetric equilibrium is the only stable spatial configuration towards which the economy will converge. We conclude that for $\eta=0.1247$ there is no agglomeration and firms in the largest country are indifferent between colluding and not colluding, while firms in the smallest country do not collude.

Figure 6e plots the indirect utility difference for $\eta=0.4$. It can be shown (see Appendix D) that for this value of $\eta$ firms do not collude for $0.1954<\lambda<0.8046$, firms collude in $H$ and not in $F$ for $\lambda>0.8046$, and firms collude in $F$ and not in $H$ for $\lambda<0.1954$. In this case the higher fine rules out simultaneous collusion, since higher profits in the domestic markets are needed to compensate the costs of the higher fine. As a result, firms will run the risk of being fined only when they operate in a sufficiently agglomerated market. The phase line exhibits therefore two discontinuities towards which the economy will converge. We conclude that for $\eta=0.4$ there is partial

\footnotetext{
${ }^{14}$ These threshold values can be visualized in Figure 5 by noticing that the first tickmark on the ordinates starting from the bottom corresponds to $\eta=0.04$. Then, drawing an imaginary horizontal line from $\eta=0.04$ we cross the competition zones at $\lambda=0.3217$ and $\lambda=0.6783$.

${ }^{15}$ Again, these threshold values can be visualized in Figure 5, by drawing an imaginary horizontal line from $\eta=0.08$.
} 
agglomeration and firms in the largest country are indifferent between colluding and not colluding, while firms in the smallest country do not collude. We note at this point that if migration had not been possible an expected fine of 0.4 would have induced all firms to not collude. To see this graphically, take the symmetric equilibrium as the exogenous spatial configuration in the absence of migration and refer to Figure 5 where for $\eta=0.4$ and for $\lambda=0.5$ we are in the white area of no collusion. ${ }^{16}$ Therefore, migration attenuates the effectiveness of the antitrust policy in eliminating collusive behavior.

Figure $6 \mathrm{f}$ plots the indirect utility difference for $\eta=0.8$. The symmetric spatial configuration is unstable while the core-periphery configurations are stable. We see in Figure 5 that firms never collude when the expected fine rate is this high. We conclude that for $\eta=0.8$ there is full agglomeration and non-collusion.

The results of Figure 6 can be summarized by the bifurcation diagram depicted in Figure 7. The bifurcation diagram has $\eta$ on the abscissa reflecting the evolution of stable and unstable spatial configurations as $\eta$ changes. Bold lines indicate stable spatial configurations, while the dashed horizontal line represents the only unstable spatial equilibrium (the symmetric equilibrium). The different intensities of gray recall those of Figure 5: in the dark-gray area firms in both countries collude, in the white area firms collude in neither country, in the light-gray area firms in the largest market collude.

For $\eta=0$ we have two partial agglomeration equilibria in which all firms collude in their local markets. A small increase in $\eta$ will push these two stable spatial equilibria further apart until $\eta$ reaches the value $\eta=0.0511$ beyond which the two equilibria move closer to each other. Then, again they move apart until they reach the maximum possible distance between them.

Intuitively, this non-linearity can be explained as follows. For low fines simultaneous collusion is a possible outcome for firms, but a spatial configuration where all firms collude is stable only if the level of agglomeration is increasing in the fine level. With a tougher antitrust policy collusion in both countries is still possible, but there are no stable spatial configurations compatible with this market structure. The economy will end up in one of the two limit points in Figure 6c, where there will be collusion in only one market. Since, as shown in Figure 5, the range of $\lambda$ for which simultaneous collusion is possible narrows with $\eta$, the two limit points tend to converge towards the symmetric equilibrium. Afterwards, an even tougher antitrust policy will rule out the possibility of having simultaneous collusion in both countries and will require higher profits to cover the possible costs of a fine. Higher profits, in turn, will be possible only with higher agglomeration in one market, that is why the limit points, which mark the critical levels of $\lambda$ at which producers are indifferent if colluding or not, move far apart as $\eta$ increases. Finally, for a very high fine, collusion is never profitable for firms and the economy works as in Section 4, where for such level of trade costs core-periphery equilibria are stable.

\footnotetext{
${ }^{16}$ The symmetric equilibrium is unstable but in the absence of migration its stability is not an issue. Had we taken any of the stable configurations at $\eta=0$ as initial configurations, i.e., $\lambda=0.3934$ or $\lambda=0.6066$, we would have had the same conclusion; namely, that an expected fine of 0.4 would eliminate collusion if migration were no possible.
} 
Coming to the effect of the antitrust policy on collusive behavior, we see that within each zone of collusion (dark-gray and light-gray) changes in the severity of the policy are ineffective on firms behavior. In the dark-grey area of Figure 7 the policy is ineffective because it is not strong enough, but in the light-grey area of Figure 7 an increase in severity of the antitrust policy is ineffective because migration neutralizes it. As already mentioned above, a higher fine requires a larger number of colluding firms for collusion to remain in place. Domestic firms will find it profitable to collude only when operating in the largest market and this is possible provided that the positive effects of higher profits on wages are higher than the negative effects on consumer surplus, so that workers will locate in the collusive market. Under these circumstances, migration would make a non-sufficiently incisive antitrust policy ineffective.

Four main conclusions can be drawn from this analysis all of which highlight the interaction between two seemingly unrelated issues: antitrust policy and location of firms. We do not know of any other paper where such interaction is explicitly studied. The first conclusion is that the antitrust policy influences the economic geography. In changing the incentives to collude the antitrust policy directly affects prices and therefore wages and consumers' surplus thereby influencing location decisions. Second, that the effect of the antitrust policy on the economic geography is non-monotonic: starting from no antitrust policy, a weak antitrust policy will increase the degree of agglomeration, a tougher policy will reduce the degree of geographical agglomeration and further increases in toughness will induce an increase in the degree of agglomeration until complete agglomeration is reached. Third, a small increase in the toughness of the anti-trust policy from zero will not eliminate the collusive behavior; a further increase will leave firms indifferent between colluding and not colluding; and further increases will eliminate collusion only when complete agglomeration is reached. Fourth, the antitrust policy would be more effective in eliminating collusion if migration were not possible.

Figure 8 plots a bifurcation diagram analogous to that in Figure 7 but for a low level of trade costs, $\tau=0.03 .{ }^{17}$ In this case the symmetric spatial configuration is stable for any value of $\eta$, there is collusion for $\eta<0.1247$ and non-collusion for higher values of $\eta$.

The results of the analysis in this section may be summarized as follows:

Simulation result 1 An increase of the fine on collusive behavior has a non monotonic effect on the degree of agglomeration when trade costs are high; first increasing it, then decreasing it, then increasing it again until complete agglomeration is reached. When trade costs are low the fine has no impact on the degree of agglomeration.

What is interesting of this result is that the antitrust policy, typically designed to fight collusive behavior, may bear collateral effects on the seemingly unrelated issue of the geographical location of industries.

Simulation result 2 Migration attenuates the effectiveness of the antitrust policy in eliminating collusive behavior.

\footnotetext{
${ }^{17}$ Intermediate levels of trade cost give a bifurcation diagram similar to that in Figure 7.
} 
This result is interesting because it discloses an unexpected link between antitrust polices and policies that enable migration of factors.

\section{The Effect of the Antitrust Policy on Welfare}

We want to study the effect of the antitrust policy on economic welfare. For simplicity we assume that fine revenues are redistributed to consumers in a lump-sum fashion, so that the fine per se is neutral on welfare. We are concerned only with world welfare, i.e., the sum of the indirect utilities of all the individuals in the world economy. We show the results by simulating the same two representative cases of high and low trade costs as in the previous section; respectively, $\tau=1.73$ and $\tau=0.03$.

Before we start the detailed analysis it is useful to grasp the intuition for the results. The effect of the antitrust policy on welfare goes through two channels: (1) the effect on oligopolistic prices (collusive or non-collusive) and (2) the effect on the spatial configuration of economic activity. It is intuitive that, other things equal, collusive oligopolies will yield lower welfare than non-collusive oligopolies simply because the deadweight loss due to price distortion is smaller in the latter than in the former. The first channel therefore conveys a positive effect of the antitrust policies on welfare. The second channel carries an effect that may be positive or negative. To see it through we have to distinguish three cases: non-collusive oligopoly, collusive oligopoly in one country only, and collusive oligopoly in both countries.

Consider first the case of two non-collusive national oligopolies. In such case the welfare function is a strictly concave symmetric parabola in $\lambda$ with a unique global maximum at $\lambda=1 / 2$ for high trade costs (the symmetric equilibrium therefore yields higher welfare than any other configuration); conversely, for low trade costs the welfare function is a symmetric convex parabola in $\lambda$ with unique minimum at $\lambda=1 / 2$ (the symmetric equilibrium yields lower welfare than any other configuration). The logic of this result is that for high trade costs the welfare loss from agglomeration (represented by the numéraire lost in transit) outweighs the benefit from agglomeration (represented by increased local competition and, thereby, lower local deadweight loss). For low trade costs the balance is reversed. Another way to see this is to note that the threshold level of trade cost at which the welfare function reaches its stationary point is lower the higher the degree of product differentiation (since oligopolistic markups are higher) and higher the higher the increasing returns in the manufacturing sector (since the benefits of agglomeration are likely to prevail).

Consider now the case of two collusive national oligopolies. In this case the welfare function is a concave symmetric parabola in $\lambda$ with unique global maximum at $\lambda=1 / 2$ for any level of trade costs. The logic of this result is simple: in the presence of collusion agglomeration will not generate welfare gains in terms of an increase in the intensity of local competition. Therefore any agglomeration will bring about a reduction in world welfare because of the increase in the quantity of the numéraire lost in transit. The balance between the two channels will determine the welfare effect of the antitrust policy.

This same logic applies to the case of collusive oligopoly in one country and non- 
collusive oligopoly in the other country, the reason is that collusion takes place in the largest country.

Figures 9 and 10 plot the welfare function against $\eta$ for the case of high and low transport costs; respectively, $\tau=1.73$ and $\tau=0.03$.

Figure 9 depicts the case of high trade costs. For $\eta<0.0511$ welfare is decreasing in $\eta$. The reason is that for these low values of $\eta$ all firms of the economy collude (see Figure 5), stable equilibria tend to be more agglomerated (see Figure 7) and this is detrimental to welfare.

For $0.0511<\eta<0.6694$ we have two welfare functions because in all stable spatial configurations corresponding to these values of $\eta$ firms located in the largest market are indifferent between colluding and not colluding and the prevailing status quo may be of collusion or non-collusion. If the status quo is of non-collusion the corresponding welfare function in the figure is titled "firms do not collude". If the status quo is of collusion the corresponding welfare functions are titled "all firms collude" or "firms in $H$ or $F$ collude" according to which of the cases applies. ${ }^{18}$

Consider now values of $\eta \in(0.0511,0.1247)$. For these values of $\eta$ both welfare functions are increasing in $\eta$ because, as we have learnt in Figure 6, the two stable spatial configurations move closer to each other and under collusion dispersion is always welfare augmenting. Obviously, the welfare function "all firms collude" is below the welfare function "firms in $H$ or in $F$ collude" since the latter contains a smaller deadweight loss. For values of $\eta \in(0.1247,0.6694)$ both welfare functions are decreasing in $\eta$ because, as we have learnt in Figure 6 , the stable spatial configurations get further apart. This is because for high trade costs, whether firms do not collude or collude in only one market, a higher agglomeration of oligopolistic firms in one location reduces welfare by inducing an excessive increase in prices of manufactures and so implying higher deadweight losses.

Clearly, for values of $\eta>0.6694$ there is no collusion and welfare is independent from $\eta$ since $\eta$ does not influence the position of the stable spatial configurations.

Figure 10 depicts the case of low trade costs. We have learnt from Figure 8 that when trade costs are this low $\eta$ does not influence the economic geography. The expected fine $\eta$ influences only the decision of colluding or not. For for $\eta<0.1247$ there is collusion and welfare is at a low level constant with respect to $\eta$. For 0.1247 $<\eta<1$ there is no collusion and welfare is at a high level constant with respect to $\eta$.

The results of the numeric analysis in this section may be summarized as follows:

Simulation result 3 A toughening of the antitrust policy may be welfare reducing even when it eliminates collusive-behavior. The antitrust policy is more likely to be welfare improving as economic integration progresses.

What is interesting of this numerical exploration is not that the antitrust policy may increase welfare, after all that is precisely what is expected from these policies.

\footnotetext{
${ }^{18}$ Thus, if we read Figure 9 from low to high values of $\eta$ the collusive status quo prevails since for the lowest values of $\eta$ there is collusion. It follows that the relevant welfare function is always the lowest. Conversely, if we read Figure 9 from high to low values of $\eta$ the non-collusive status quo prevails since for the highest values of $\eta$ there is no collusion. It follows that the relevant welfare function is always the highest.
} 
What is interesting is the possibility that the antitrust policy, though successful eliminates collusion, results in welfare reduction. Intuitively, this is the consequence of the displacement effects of the antitrust policy. When trade costs are sufficiently high, agglomeration would always be detrimental to welfare, whether firms collude or not.

\section{Conclusions}

The objective of this paper has been to study the consequences of the market structure on economic geography and welfare. We have replaced monopolistic competition with oligopoly. We have shown that the likelihood of complete agglomeration is higher in oligopoly than monopolistic competition. In the presence of national oligopolies (collusive or not) there is a rich variety of stable spatial configurations (which includes multiple stable configurations), but for low enough trade costs the symmetric equilibrium is stable. The stability of the symmetric equilibrium for low trade costs is a result that marks an important difference between oligopoly and monopolistic competition. We then moved to the analysis of the effects of the antitrust policy. We have highlighted the collateral consequences of the antitrust policy on economic geography. We have also found that the possibility of migration attenuates the ability of the antitrust policy to eliminate collusion even when the policy is implemented by all governments with the same severity. Lastly, we have shown that the antitrust policy is welfare reducing when its negative effect conveyed through the economic geography outweighs its positive effect transmitted through prices.

\section{References}

[1] Baldwin, R. E., Forslid, R., Martin, P., Ottaviano, G.I.P, Robert-Nicoud, F., 2005. Economic Geography and Public Policy. Princeton and Oxford: Princeton University Press.

[2] Brülhart, M., Trionfetti, F., 2004. Public Expenditure, International Specialisation and Agglomeration. European Economic Review, 48, 851-881.

[3] Combes, P-Ph. 1997. Industrial agglomeration under Cournot competition. Annales d'Economie et de Statistique 45: 161-182.

[4] Connor, J.M., 2005. Price-fixing overcharges: legal and economic evidence. Staff Paper No. 04-17, Department of Agricultural Economics, Purdue University, West Lafayette, IN. Appendix tables are available online: http://www.agecon.purdue.edu/staff/connor/papers/Price_Fixing_Overcharges_Appendix_Tables.pdf.

[5] Connor, J.M., 2007. Price-fixing overcharges: legal and economic evidence. In: Kirkwood, J.B. (Ed.), Research in Law and Economics, vol. 22. Oxford, Amsterdam and San Diego: Elsevier, 59-153.

[6] d'Aspremont, C., Gabszewicz, J.J., Thisse, J-F., 1979. On Hotelling's 'Stability in Competition'. Econometrica, 47, 1145-50. 
[7] Dewit, G., Leahy, D., and Montagna, C. 2003, Dundee Discussion Papers in Economics, No. 137.

[8] Dixit, A. K., Stiglitz, J.E., 1977. Monopolistic Competition and Optimum Product Diversity. American Economic Review, 67, 297-308.

[9] Fujita, M., Krugman, P.R., Venables, A.J., 1999. The Spatial Economy. Cambridge (MA): The MIIT Press.

[10] Fujita, M., Thisse, J-F., 2002. Economics of Agglomeration. Cambridge: Cambridge University Press.

[11] Head, K., Mayer, T., 2000, Non Europe: The Magnitude and Causes of Market Fragmentation in Europe, Weltwirtschaftliches Archiv, 136, 285-314.

[12] Head, K., Mayer, T., J. Ries, J., 2002. On the Pervasiveness of Home Market Effects. Economica, 69, 371-390.

[13] Helpman, E. 1998. The Size of Regions. In Pines, D., Sadka, E., Zilcha, I. (Eds.). Topics in Public Economics. Theoretical and Applied Analysis. Cambridge: Cambridge University Press, 33-54.

[14] Hotelling, H., 1929. Stability in Competition. Economic Journal, 39, 41-57.

[15] Krugman, P. R., 1991. Increasing Returns and Economic Geography. Journal of Political Economy, 99, 483-99.

[16] Ludema, R. D., Wooton, I., 2000. Economic Geography and the Fiscal Effects of Regional Integration. Journal of International Economics. 52, 331-357.

[17] McCallum, J., 1995, "National Borders Matter: Canada-US Regional Trade Patterns", American Economic Review, 85, 615-623.

[18] Ottaviano, G. I. P., Tabuchi, T., Thisse, J-F., 2002. Agglomeration and Trade Revisited. International Economic Review, 43, 409-435.

[19] Puga, D., 1999. The Rise and Fall of Regional Inequalities. European Economic Review, 43, 303-334.

[20] Zhou, H., 2007. Oligopolistic Competition and Economic Geography. Journal of Regional Sciences 47, 915-933.

\section{Appendix}

Section A. Full derivation of the utility gap $\Delta V(\lambda)$ can be obtained from (10) by substituting the equilibrium wages and consumer surplus in regions $H$ and $F$ associated with the equilibrium prices prevailing under international oligopoly:

$$
\Delta V(\lambda)=C\left(\tau_{c}-\tau\right) \tau(\lambda-1 / 2),
$$


with $C>0, \tau_{c}>0$ where $\tau_{c}>\tau_{c}^{M C}=4 \frac{a \phi(3 b \phi+2 c N \phi)}{2 b \phi(3 b \phi+3 c N \phi+c A)+c^{2} N \phi(A+N \phi)}$, that is $\tau_{c}$ is larger than the corresponding critical level of transportation costs in monopolistic competition $\tau_{c}^{M C}$. For full derivation details, see MAPLE file Appendix_A.

Section B. In the case of national oligopoly the indirect utility gap $\Delta V(\lambda)$ can be obtained from (10) by substituting the equilibrium wages and consumer surplus in regions $H$ and $F$ associated with the equilibrium prices (12)-(15). In the MAPLE file Appendix_B we show that the slope of $\Delta V(\lambda)$ at $\lambda=1 / 2$ is a quadratic function of trade $\operatorname{costs} \tau$ of the form

$$
\left.\frac{d \Delta V(\lambda)}{d \lambda}\right|_{\lambda=\frac{1}{2}}=-B_{0}^{N C}+B_{1}^{N C} \tau-B_{2}^{N C} \tau^{2},
$$

where $B_{0}^{N C}, B_{1}^{N C}$, and $B_{2}^{N C}$ are positive. The polynomial in (B-1) is a concave parabola. Since it is quadratic in $\tau$ there may be two distinct positive tau-break. By Descartes' sign rule we know that the polynomial has roots with positive real parts.

In the same file, we evaluate the indirect utility difference at $\lambda=1$ or $\lambda=0$ in order to study the stability of the core-periphery configurations. Computing, for instance, $\Delta V(1)$ we have:

$$
\Delta V(1)=-S_{0}^{N C}+S_{1}^{N C} \tau-S_{2}^{N C} \tau^{2}
$$

where $S_{0}^{N C}, S_{1}^{N C}$, and $S_{2}^{N C}$ are positive. The polynomial in (B-2) is a concave parabola. Since it is quadratic in $\tau$ there may be two distinct and positive tau-sustain.

Since each of the polynomials in (B-1)-(B-2) may have real and distinct roots, or real and coincident roots, or complex roots we have a total of sixteen possible bifurcation diagrams as discussed in the text. For further details, see MAPLE file Appendix_B.

Section C. In the MAPLE file Appendix_C we study the stability analysis of collusive national oligopoly by showing that using equilibrium prices (21)-(24) we have that:

$$
\begin{gathered}
\left.\frac{d \Delta V(\lambda)}{d \lambda}\right|_{\lambda=\frac{1}{2}}=-B_{0}^{C}+B_{1}^{C} \tau-B_{2}^{C} \tau^{2}, \\
\Delta V(1)=-S_{0}^{C}+S_{1}^{C} \tau-S_{2}^{C} \tau^{2},
\end{gathered}
$$

where all parameters are positive.

Section D. Consider the locus in the space $(\lambda, \eta)$ for which firms located in $H$ are indifferent between colluding or not:

$$
(1-\eta) \pi_{H H}^{C}-\pi_{H H}^{N C}=0
$$

Let $\eta_{H}$ denote the value of the fine $\eta$ satisfying (D-1). In the MAPLE file Appendix_D we show the critical level $\eta_{H}$ does not depend upon the level of trade costs $\tau$. Further, $\eta_{H}$ can be expressed in function of $\lambda$ as follows:

$$
\eta_{H}=\frac{(\lambda-1 / N)\left(D_{H, 3} \lambda^{3}+D_{H, 2} \lambda^{2}-D_{H, 1} \lambda+D_{H, 0}\right)}{-\Lambda_{H}(\lambda)}
$$


where $D_{H, 3}, D_{H, 2}, D_{H, 1}, D_{H, 0}>0$ and $\Lambda_{H}(\lambda)=[c N(1-\lambda)+b]\left\{(2 b+c N)[c-2(b+c N)]+c^{2} N \lambda\right\}^{2}>0$.

In the companion file Appendix_D we also show that the critical fine $\eta_{H}$ is always increasing in $\lambda$ for $\lambda \in(1 / N, 1)$.

For the representative firm located in $F$ analogous results can be easily obtained by symmetry. 


\begin{tabular}{|c|c|c|c|c|c|}
\hline \multicolumn{6}{|c|}{ Table 1} \\
\hline Year & Market & Code No. & $\begin{array}{l}\text { Domestic } \\
\text { Members }\end{array}$ & $\begin{array}{r}\text { Other EU } \\
\text { National } \\
\text { Members }\end{array}$ & $\begin{array}{l}\text { Non-EU } \\
\text { National } \\
\text { Members }\end{array}$ \\
\hline 2001 & Belgian beer market & 37.614 & 3 & 1 & \\
\hline 2001 & $\begin{array}{l}\text { Bank charges } \\
\text { Germany }\end{array}$ & 37.919 & 5 & & \\
\hline 2001 & $\begin{array}{c}\text { Luxembourg brewing } \\
\text { industry }\end{array}$ & 37.800 & 4 & & \\
\hline 2002 & $\begin{array}{c}\text { Dutch industrial } \\
\text { gases cartel }\end{array}$ & 36.700 & 7 & & \\
\hline 2002 & $\begin{array}{c}\text { Austrian banks } \\
\text { in Lombard Club } \\
\text { cartel case }\end{array}$ & 36.571 & 9 & & \\
\hline 2003 & French beef & 38.279 & 6 & & \\
\hline 2004 & $\begin{array}{c}\text { French beer } \\
\text { market }\end{array}$ & 37.750 & 3 & 1 & \\
\hline 2004 & $\begin{array}{c}\text { Spanish raw } \\
\text { tobacco market }\end{array}$ & 38.238 & 8 & 1 & \\
\hline 2005 & Italian raw tobacco & 38.281 & 4 & & \\
\hline 2006 & Bitumen Nederland & 38.456 & 9 & 4 & 1 \\
\hline 2007 & Bitumen Spain & 38.710 & 2 & 3 & \\
\hline 2007 & $\begin{array}{l}\text { Netherlands } \\
\text { beer market }\end{array}$ & 37.766 & 5 & 1 & \\
\hline 2008 & $\begin{array}{c}\text { International removal } \\
\text { services in Belgium }\end{array}$ & 38.543 & 10 & 1 & \\
\hline 2009 & $\begin{array}{l}\text { Concrete reinforcing bar } \\
\text { sector in Italy }\end{array}$ & 37.956 & 13 & & \\
\hline & Total & & 88 & 12 & 1 \\
\hline
\end{tabular}

Source: Our elaboration from the European Commission website, http://ec.europa.eu/competition/cartels/cases/cases.html 


\begin{tabular}{|c|c|}
\hline Table 2 & \\
\hline & Baseline parameter values \\
\hline $\bar{L}=1$ & labor supply in manufacturing \\
\hline$A=2.2$ & labor force in agriculture \\
\hline$\alpha=10$ & preference parameter \\
\hline$\beta=20$ & preference parameter \\
\hline$\gamma=10$ & preference parameter \\
\hline$\phi=0.1$ & technology parameter \\
\hline$N=10$ & number of firms \\
\hline & Implied critical values of $\tau$ \\
\hline Non-collusive $n$ & tional oligopoly \\
\hline$\tau_{\text {trade }}^{N C}=1.7355$ & threshold level for trade costs \\
\hline$\tau_{b 1}^{N C}=0.0394$ & first break point \\
\hline$\tau_{b 2}^{N C}=2.2182$ & second break point \\
\hline$\tau_{s 1}^{N C}=0.3942$ & first sustain point \\
\hline$\tau_{s 2}^{N C}=2.2006$ & second sustain point \\
\hline Collusive nation & al oligopoly \\
\hline$\tau_{\text {trade }}^{C}=3.4634$ & threshold level for trade costs \\
\hline$\tau_{b 1}^{C}=1.5468$ & first break point \\
\hline$\tau_{b 2}^{C}=2.0676$ & second break point \\
\hline & Implied critical values of $\eta$ \\
\hline 0.1247 & critical $\eta$ for which collusion ceases to be sustainable in both countries at $\lambda=1 / 2$ \\
\hline 0.6694 & critical $\eta$ for which collusion ceases to be sustainable in $H(F)$ at $\lambda=1(0)$ \\
\hline
\end{tabular}


Figure 1: Bifurcation diagrams with two break points and two sustain points $1 a$

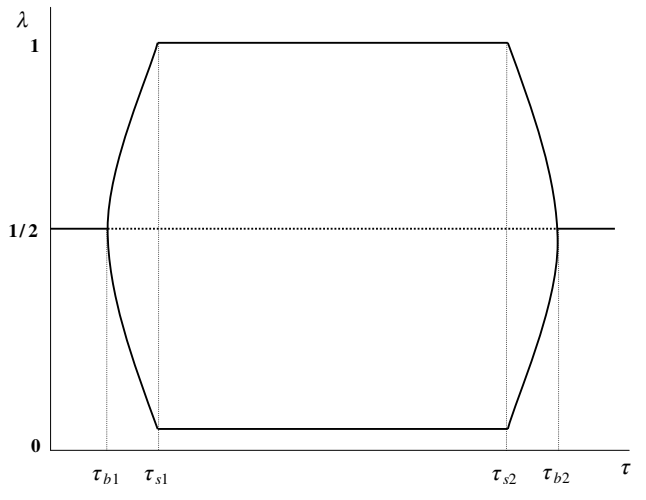

$1 \mathrm{c}$

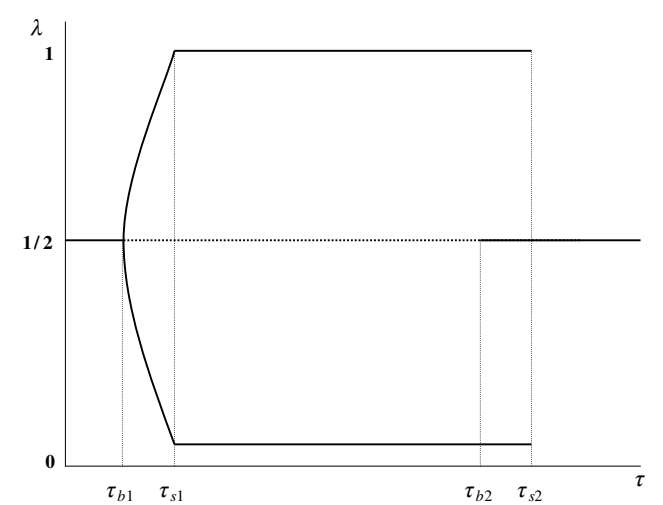

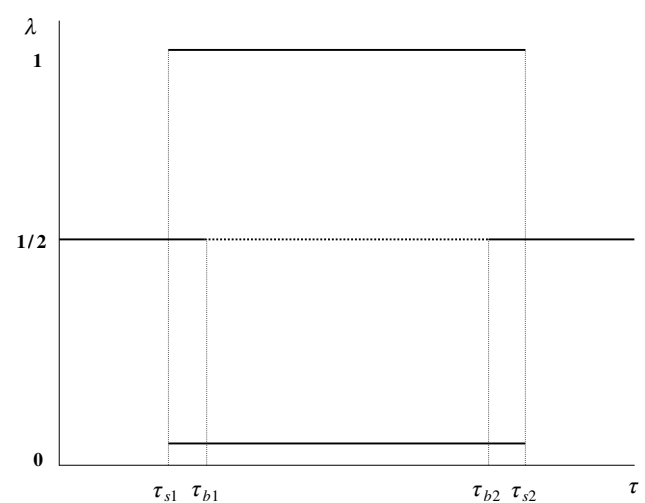

$1 d$

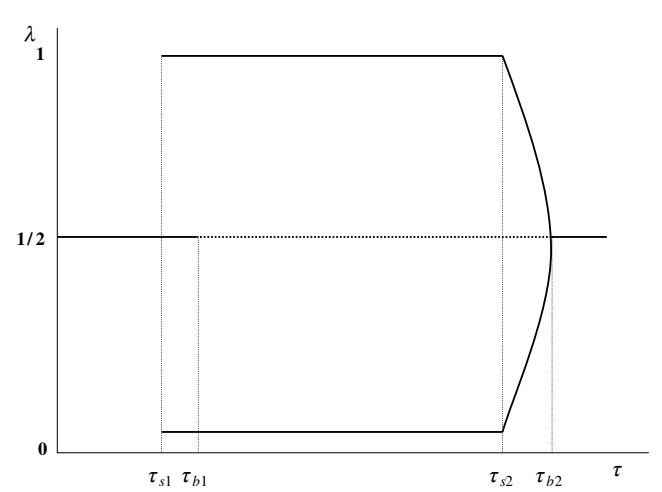


Figure 2: Bifurcation diagram with two sustain points and no break points

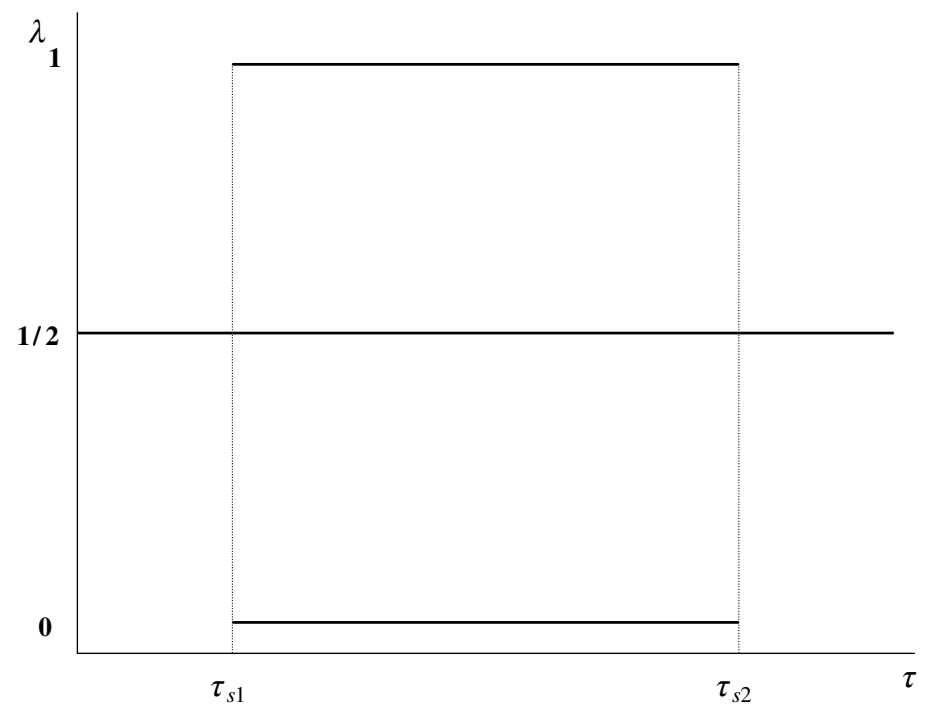

Figure 3: Bifurcation diagram with two break points and no sustain points

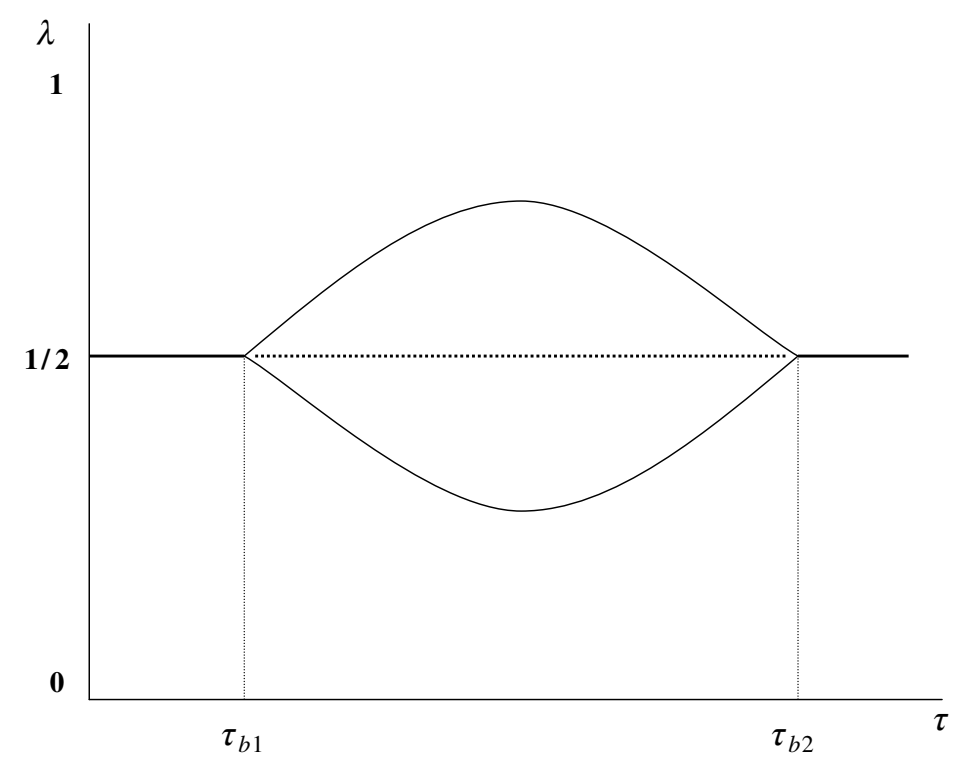


Figure 4: Bifurcation diagram with no critical points

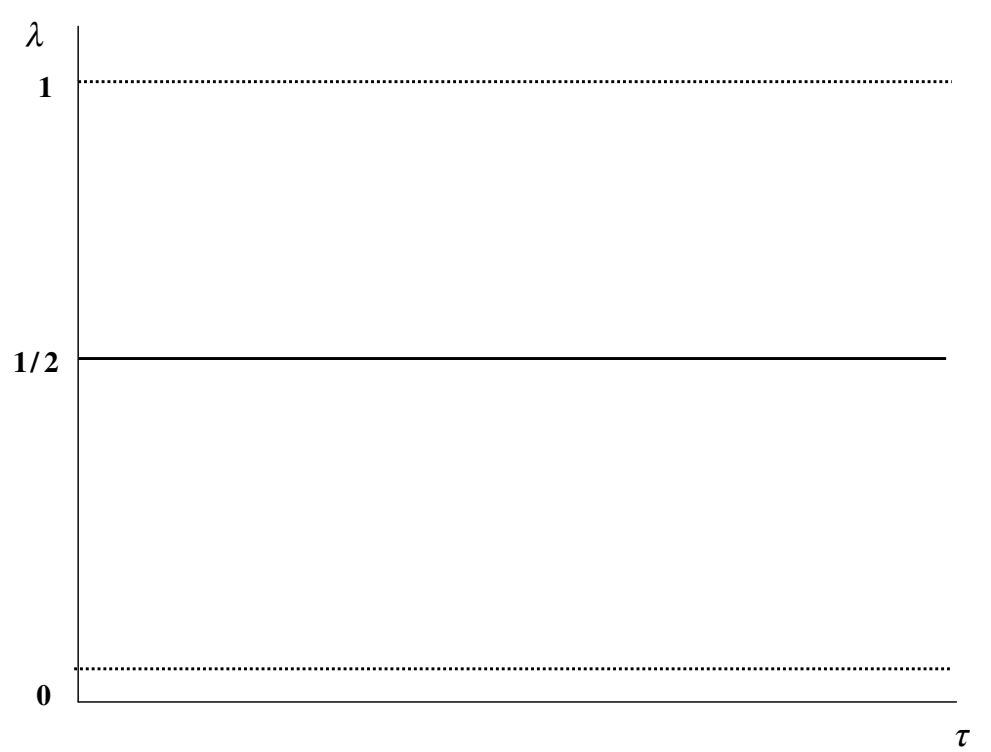


Figure 5: Competition regimes as function of $\eta$ and $\lambda$

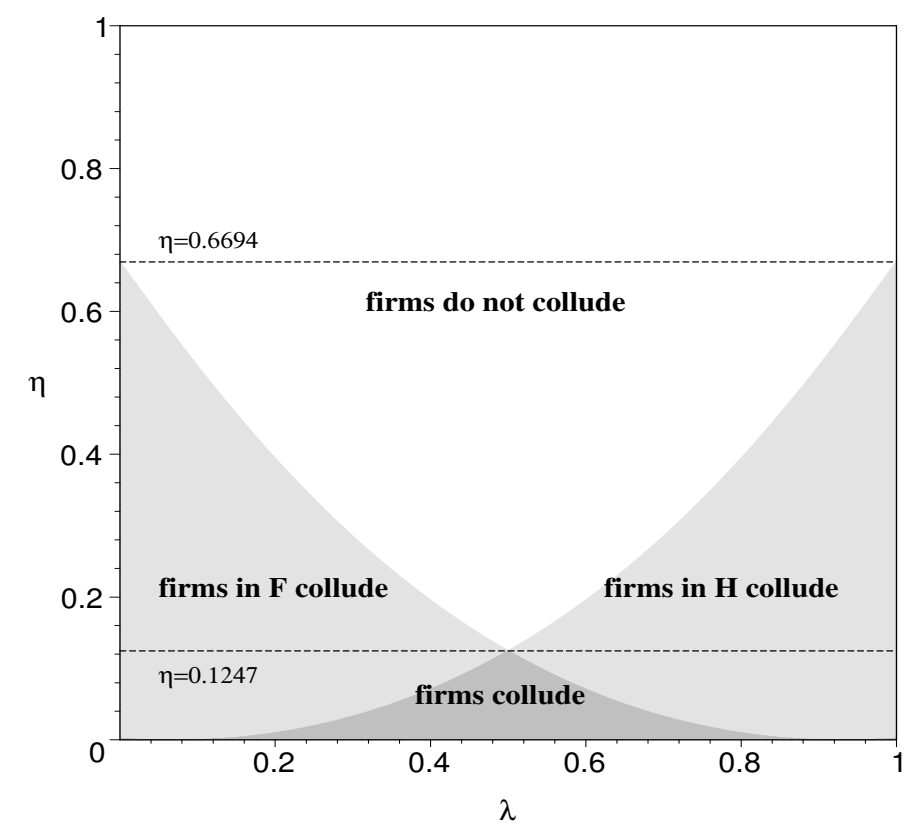


Figure 6: Phase diagrams, $\tau=1.73$
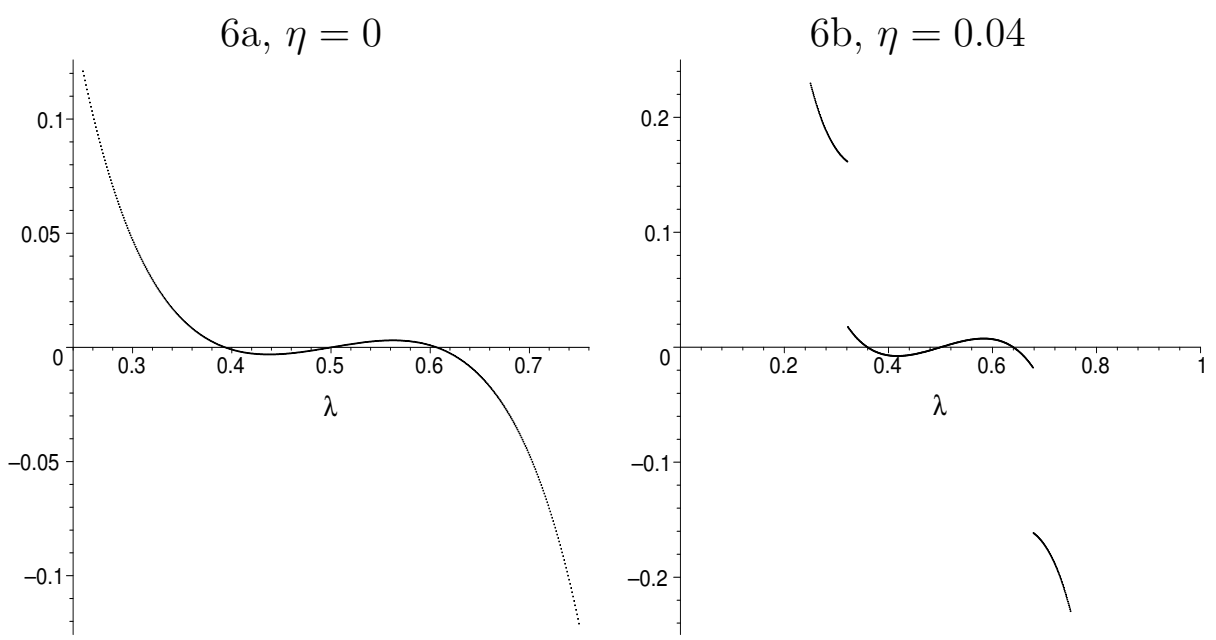

$6 \mathrm{c}, \eta=0.08$

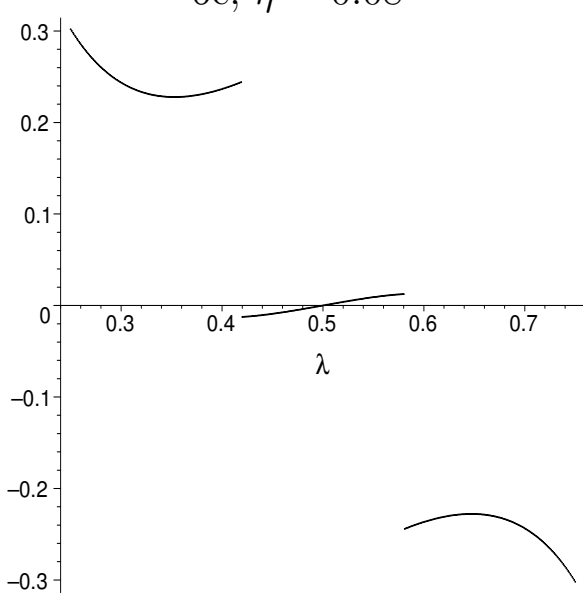

$6 \mathrm{~d}, \eta=0.1247$

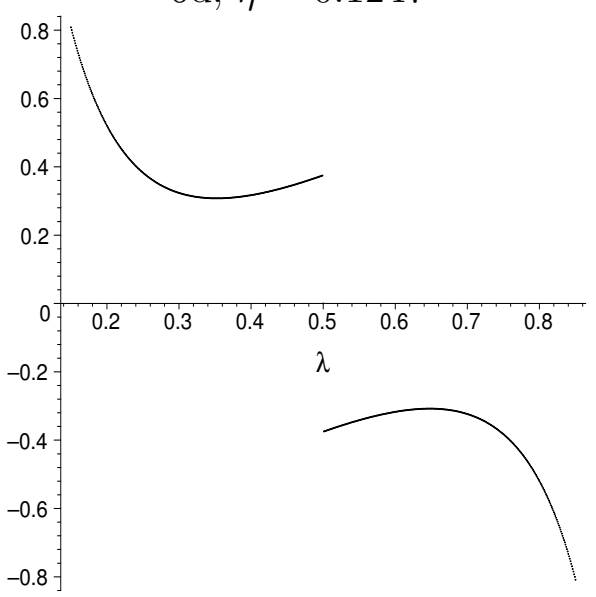

$6 \mathrm{e}, \eta=0.4$
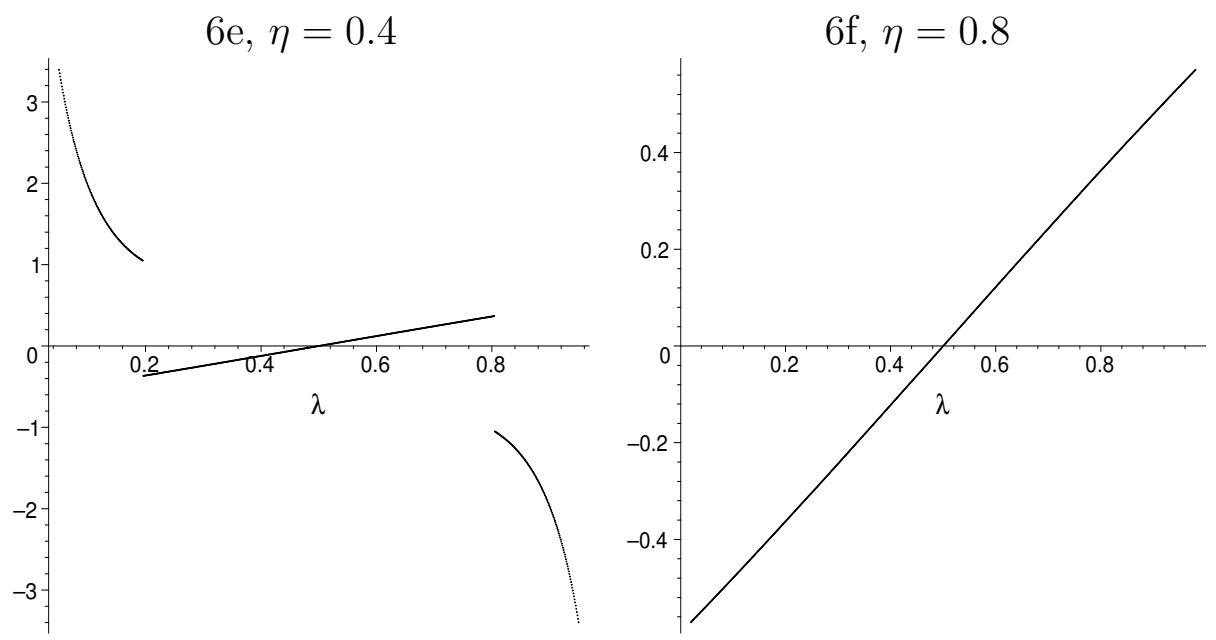
Figure 7: Bifurcation diagram, $\tau=1.73$

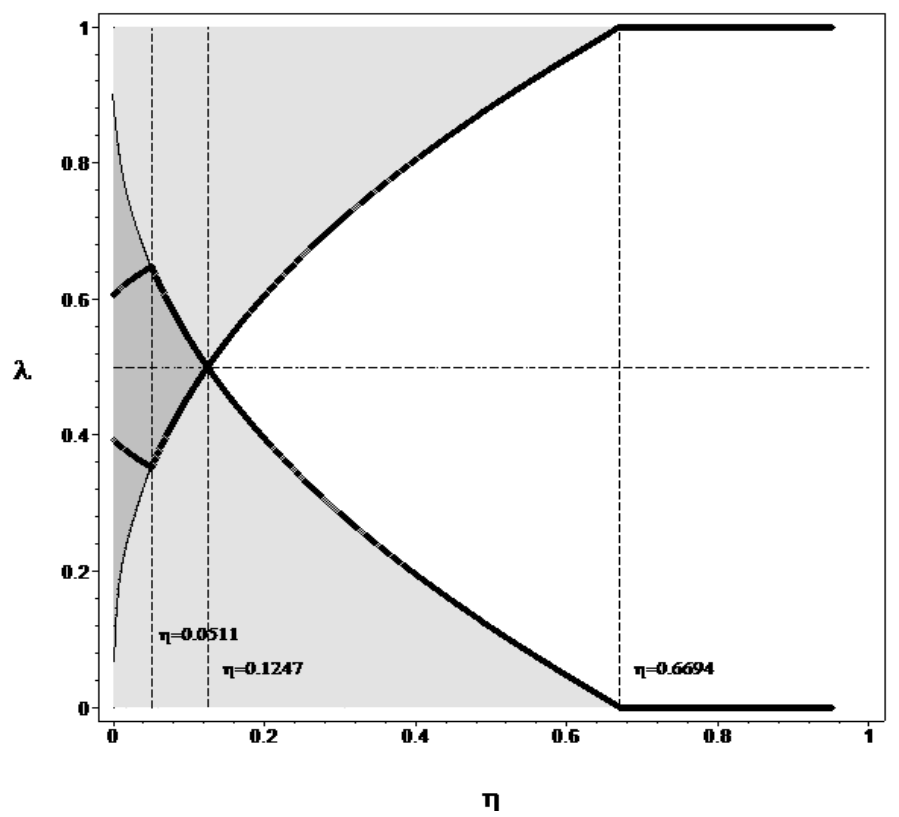

Figure 8: Bifurcation diagram, $\tau=0.03$

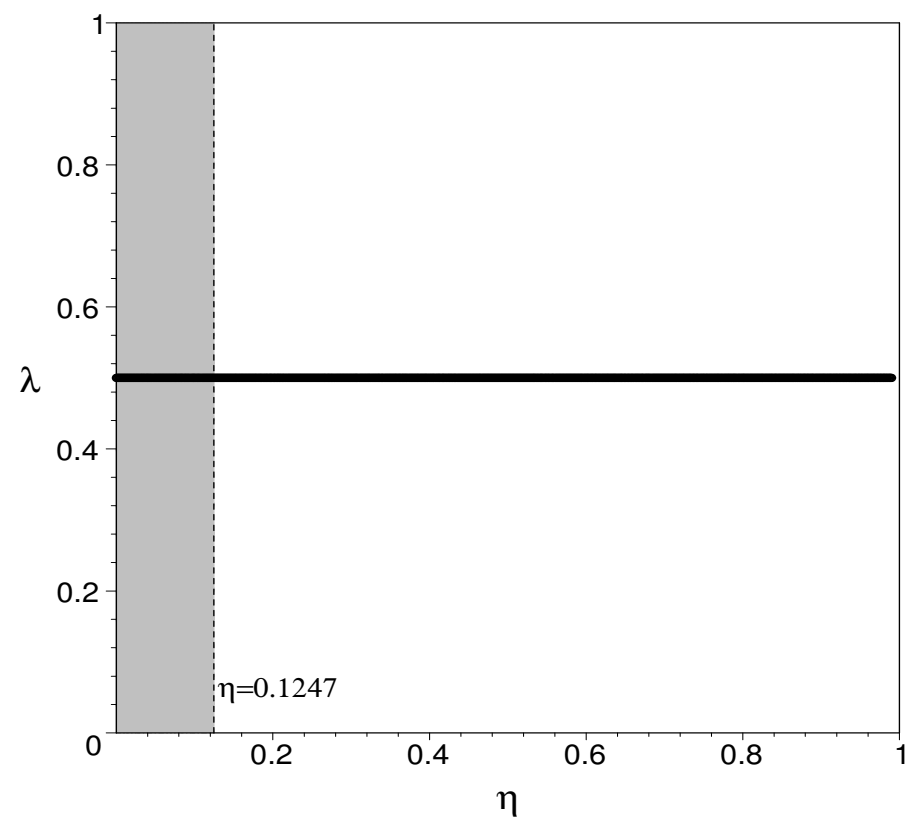


Figure 9: Welfare, $\tau=1.73$

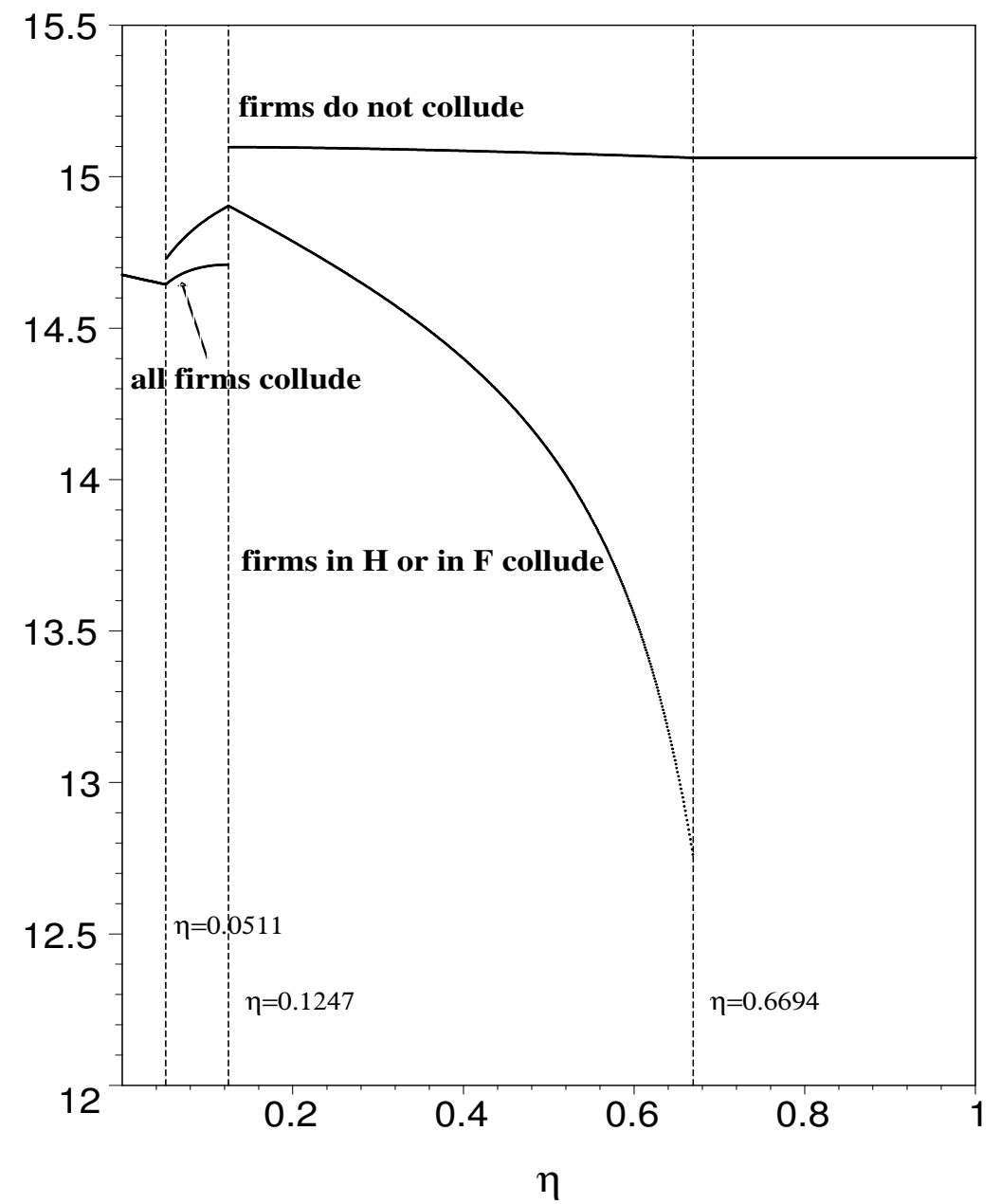


Figure 10: Welfare, $\tau=0.03$

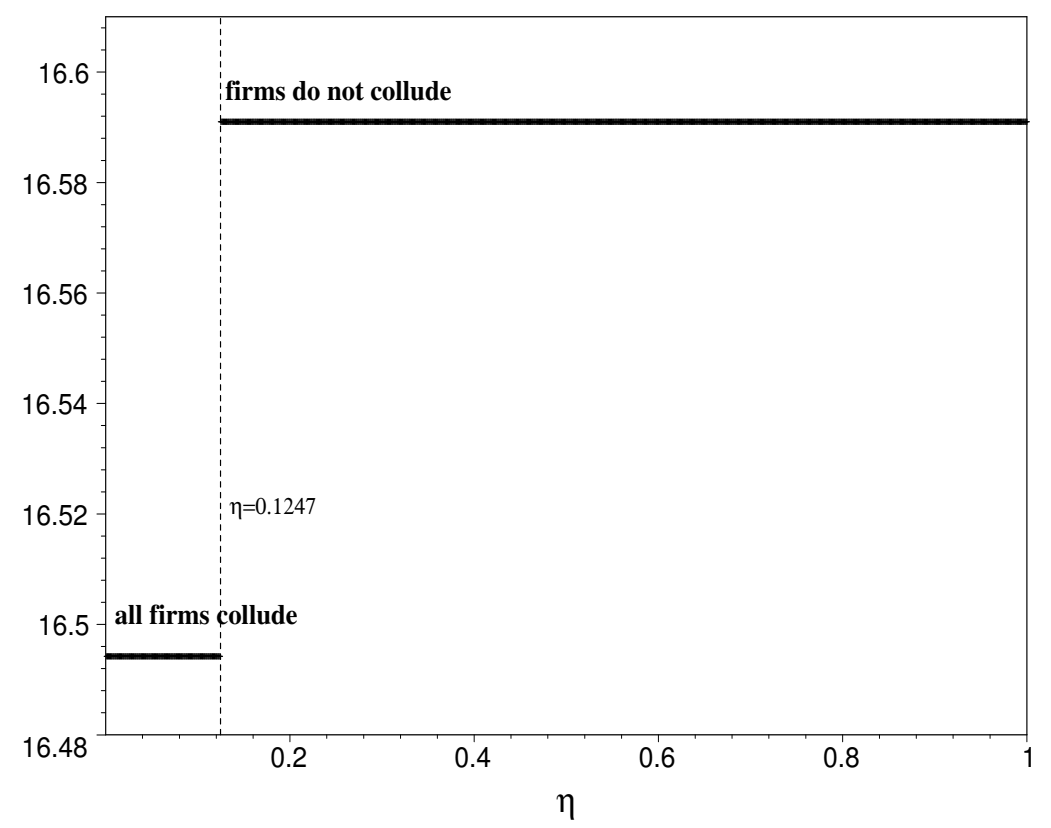

